\title{
CICLO DE CINEMA DO GEERGE: a arte promovendo o debate sobre gênero e sexualidade
}

\author{
Cristiano Eduardo da Rosa* \\ Michele Lopes Leguiça Corrêa**
}

\begin{abstract}
Resumo: Este artigo objetiva mostrar a importância do trabalho com a arte para promover o debate sobre gênero e sexualidade, a partir da proposta desenvolvida pelo GEERGE - Grupo de Estudos de Educação e Relações de Gênero - nas cinco edições do Ciclo de Cinema, ocorridas entre 2004 e 2009. Elas aconteceram na Sala Redenção, Campus Central da Universidade Federal do Rio Grande do Sul UFRGS, Porto Alegre/RS, com entrada franca e abertas à comunidade, havendo conversa com professores/as convidados/as de diversas áreas após as exibições dos filmes. Com este trabalho, por meio de uma pesquisa bibliográfica, enfatizamos a importância de operar com a arte nesta discussão, como campo potente de oportunizar e potencializar debates sobre diversidade e Direitos Humanos, uma prática que o GEERGE iniciou e contribuiu de dentro da universidade para acadêmicos e comunidade.
\end{abstract}

Palavras-chave: Arte. Ciclo de Cinema. GEERGE.

GEERGE CINEMA CYCLE: art promoting the debate about gender and sexuality

\begin{abstract}
This article aims to show the importance of working with art to promote the debate about gender and sexuality, based on the proposal developed by GEERGE - Group of Studies of Education and Gender Relations - in the five editions of the Cinema Cycle, that happened among 2004 and 2009. They took place in the Redenção Room, Central Campus of the Universidade Federal do Rio Grande do Sul UFRGS, Porto Alegre/RS, with free entrance and open to the community, there being a conversation with invited teachers from various areas after the exhibitions of movies. With this work, through a bibliographical research, we emphasize the importance of working with the art in this discussion, as a powerful field of opportunity and potentiating debates on diversity and Human Rights, a practice that GEERGE started and contributed from within the university to academics and community.
\end{abstract}

Keywords: Art. Cycle of Cinema. GEERGE

Submissão 16-11-18 Aceite 16-12 18

\section{CLAQUETE, CENA UM, TOMADA UM}

A produção cinematográfica sempre foi um artefato cultural utilizado no campo da Educação proporcionando reflexões dentro e fora da sala de aula. Concebida como uma pedagogia cultural, as narrativas fílmicas fazem parte do cotidiano dos sujeitos desde a infância, estimulando e oportunizando a imaginação e o pensamento acerca das mais variadas realidades, sejam estas ficcionais ou não.

O Ciclo de Cinema apresentado aqui para problematizar a utilização das artes nos debates sobre gênero e sexualidade configura-se como um projeto original do GEERGE - Grupo de Estudos de Educação e Relações de Gênero - em estreita vinculação com a linha de pesquisa Educação, Sexualidade e Relações de Gênero,

\footnotetext{
* Professor licenciado em Letras e em Pedagogia, mestrando em Educação na Universidade Federal do Rio Grande do Sul na linha de pesquisa Educação, Sexualidade e Relações de Gênero. Integrante do GEERGE - Grupo de Estudos de Educação e Relações de Gênero.

** Mestra em Educação (UFRGS, 2019), graduada em Educação Especial (UFSM, 2009) e integra o Grupo de Estudos de Educação Infantil e Infâncias GEIN, UFRGS.
} 
do Programa de Pós-graduação em Educação da Faculdade de Educação da Universidade Federal do Rio Grande do Sul.

Para desenvolver este estudo, utilizamos a metodologia de pesquisa bibliográfica acerca da utilização do cinema como ferramenta de fomento ao debate sobre as questões citadas acima, destacando e resgatando a fundamental contribuição do GEERGE para esse tipo de atividade com as artes em prol de discussões na perspectiva dos Direitos Humanos, que hoje tem sido tão difundida nas Instituições de Ensino Superior de todo o Brasil.

\section{CONTEXTUALIZANDO O GEERGE E O CICLO DE CINEMA}

Para destacar um breve histórico do contexto do grupo de estudos propositor do Ciclo de Cinema, relembramos que o Programa de Pós-graduação em Educação (PPGEDU) da Faculdade de Educação (FACED) da Universidade Federal do Rio Grande do Sul (UFRGS) iniciou em 1972, sendo credenciado em 1974, com o curso de Mestrado em Educação e, em 1982, com o Doutorado em Ciências Humanas - Educação.

Em 1990 a professora Guacira Lopes Louro deu início às atividades de estudos do GEERGE, registrado no Conselho Nacional de Desenvolvimento Científico e Tecnológico (CNPq). Dez anos mais tarde, a referida docente, juntamente com a professora Dagmar Estermann Meyer, resolveram criar a linha de pesquisa Educação, Sexualidade e Relações de Gênero, de modo que é possível afirmar o quanto a história do GEERGE, assim como a história da linha, se confundem e se intercruzam.

Desse modo, surgiu a ideia de se criar um Ciclo de Cinema sobre gênero e sexualidade, com a exibição de um filme que levasse no máximo uma hora e meia, seguido de um debate com algum especialista e uma representação do GEERGE, cada qual com aproximadamente quinze minutos de fala, abrindo para o debate da plateia. Os ciclos ocorreram entre os anos de 2004 e 2009.

O grupo de estudos ainda ofertou o curso de especialização em Educação, Sexualidade e Relações de Gênero, que teve duas edições entre 2008 e 2011, além do curso de Aperfeiçoamento em Diversidade e Gênero na escola: sexualidade, violência, olhares sobre práticas contemporâneas, este com três edições, ocorridas entre 2013 e 2015.

O GEERGE, cuja produção se situa na vertente de estudos de gênero pós-estruturalista, foi fundado pela professora Guacira Lopes Louro, cujas primeiras integrantes foram as professoras Dagmar Estermann Meyer e Rosângela Soares. 
A linha de pesquisa Educação, Sexualidade e Relações de Gênero, criada no inicio do ano de 2000 pelas professoras Guacira Lopes Louro e Dagmar Estermann Meyer, situa-se como parte do terceiro eixo temático do PPGEDU da UFRGS, chamado "Cultura, Currículo e Sociedade", que considera as relações entre cultura, sociedade e currículo nas suas dimensões educativas tanto produtivas quanto reprodutivas.

Essa linha toma como referência central teorizações desenvolvidas no âmbito dos Estudos Feministas, dos Estudos Culturais, dos Estudos Gays e Lésbicos e da Teoria Queer para examinar questões relacionadas a corpo, gênero, sexualidade e educação. Fazendo uso, preferentemente, da perspectiva pós-estruturalista, essas dimensões são analisadas em suas complexas articulações com outras, tais como raça/etnia, nacionalidade, classe, religião. ${ }^{1}$

Dentro da linha, há atualmente três temáticas individuais: (i) "Políticas de Corpo e de Saúde: gênero, raça e nacionalidade", coordenada pela professora Dagmar E. Meyer; (ii) "Infância, gênero e sexualidade", coordenada pela professora Jane Felipe de Souza e (iii) "Masculinidade, gênero e sexualidade", coordenada pelo professor Fernando Seffner.

No início da linha de pesquisa ainda havia outra temática, chamada "Gênero, Sexualidade e Educação", coordenada pela professora Guacira Lopes Louro, que deixou o PPGEDU da UFRGS em função de sua aposentadoria no ano de 2011 . $^{2}$

Como destacado na página do grupo no site da UFRGS

O GEERGE é um dos grupos mais antigos do Brasil, reconhecido pelo CNPq como uma instância acadêmica formadora de pesquisadores/as, reunindo estudantes e docentes interessados em investigar e discutir questões relacionadas a gênero, sexualidade, etnia, educação, em suas múltiplas e complexas articulações. ${ }^{3}$

Ao longo dos anos de existência da linha de pesquisa Educação, Sexualidade e Relações de Gênero, formaram-se diversos/as Mestres/as e Doutores/as, cujos alguns hoje são referências nos Estudos de Gênero, principalmente. De acordo com o Repositório Digital da UFRGS, o Lume, há 43 dissertações e 41 teses publicadas que foram defendidas por discentes da linha entre 2002 e $2018 .^{4}$

Docentes e estudantes da linha de pesquisa ainda têm organizado e participado de diversos livros nacionais e internacionais com as temáticas de Educação, gênero

\footnotetext{
${ }^{1}$ Disponível em: <http://www.ufrgs.br/ppgedu/educacao-sexualidade-e-relacoes-de-genero>. Acesso em: 28 out. 2018.

${ }^{2}$ No final de 2018, a professora Dagmar E. Meyer também se ausenta da linha de pesquisa tendo em vista a sua aposentadoria na instituição.

${ }^{3}$ Disponível em: <http://www.ufrgs.br/geerge>. Acesso em: 7 nov. 2018.

${ }^{4}$ Disponível em: <http://lume.ufrgs.br/handle/10183/1>. Acesso em: 7 nov. 2018.
} 
e sexualidade, assim como têm estado presentes em eventos e formações docentes, divulgando as pesquisas que são desenvolvidas no âmbito acadêmico com seus resultados parciais ou finais.

Cabe destacar aqui também que o grupo de estudos participou ativamente na criação do GE 23 (Grupo de Estudos em Gênero, Sexualidade e Educação) da ANPEd (Associação Nacional de Pós-Graduação e Pesquisa em Educação) no ano de 2003, que dois anos depois se oficializou como GT 23 (Grupo de Trabalho). ${ }^{5}$

Nesse sentido, o GEERGE tem sido referência como grupo de pesquisa por sua atuação constante e contínua desde sua criação, incentivando e inspirando também a formação de outros grupos em diversas instituições. Como exemplo recente, podemos citar o GEDD - Grupo de Estudos em Gênero, Diversidades e Direitos Humanos, da Faculdade de Direito da Universidade Estadual de Alagoas.

Foi na gestão da professora Jane Felipe como coordenadora do GEERGE, em 2004, que o Ciclo de Cinema foi iniciado, como um movimento de dar maior visibilidade a esses temas e aproveitando o fato de haver um cinema dentro da universidade. $\mathrm{O}$ propósito do ciclo era centrar nas temáticas de gênero e sexualidade no terreno da cultura, "colocando em questão distintas perspectivas para compreender e significar as masculinidades e feminilidades contemporâneas" (FELIPE, 2007, p. 124).

O GEERGE foi um dos primeiros grupos de estudos de dentro da universidade a fazer essa atividade de exibir filmes e, a partir deles, realizar discussões, o que atualmente é uma prática bastante comum entre grupos de outras instituições. Alguns dos filmes que fizeram parte do Ciclo de Cinema foram "O segredo de Brokeback Mountain" (EUA, 2005), "Meninos não choram" (EUA, 1999), "Todas as cores do amor” (Irlanda, 2003), “Transamérica” (EUA, 2005), “Menina Má.com” (EUA, 2005), "O céu de Suely" (Brasil / França / Alemanha, 2006) e "Volver" (Espanha, 2006).

Os debates, após a projeção de cada filme, contavam com a presença de dois ou três convidados especiais, como analistas culturais, antropólogos/as, cineastas, educadores/as e psicólogos/as, entre outros, que atuavam como estimuladores ou provocadores da discussão entre os/as participantes. Alguns debatedores/as que participaram do Ciclo de Cinema foram Fernando Mascarello, Cláudia Ribeiro, Ruth Sabat, Luiz Henrique dos Santos e Rosângela Soares, além dos professores da linha de pesquisa - Guacira Lopes Louro, Jane Felipe e Fernando Seffner.

5 Disponível em: <http://www.anped.org.br/grupos-de-trabalho/gt23-g\%C3\%AAnero-sexualidade-eeduca\%C3\%A7\%C3\%A3o>. Acesso em: 8 nov. 2018. 
Havia um cuidado com a escolha dos filmes para que tivessem no máximo uma hora e meia, a fim de que a atividade não se tornasse algo cansativo para os/as participantes. Os/As debatedores/as comentavam cerca de quinze minutos e depois seguiam para o debate com a participação do público em geral.

Em 2010 realizou-se também o "Ciclo das Artes: gênero e sexualidade no cinema e no teatro", como uma atividade de extensão universitária, com certificação e gratuidade, proposta pelo grupo de estudos nos mesmos moldes do Ciclo de Cinema do GEERGE, inclusive no mesmo local, em parceria com o grupo Teatro Sarcáustico.

Os filmes exibidos nessa atividade, que ocorreu entre agosto e dezembro de 2010 e dentro de uma programação de comemoração dos 20 anos do GEERGE, foram: Estômago (Brasil, 2007), XXY (Argentina / França / Espanha, 2007), Educação (Inglaterra, 2009), É Proibido Fumar (Brasil, 2009) e Jogo de Cena (Brasil, 2007). Abaixo, a imagem de divulgação da extensão universitária:

IMAGEM - Cartaz do evento Cinema, Gênero e Sexualidade.

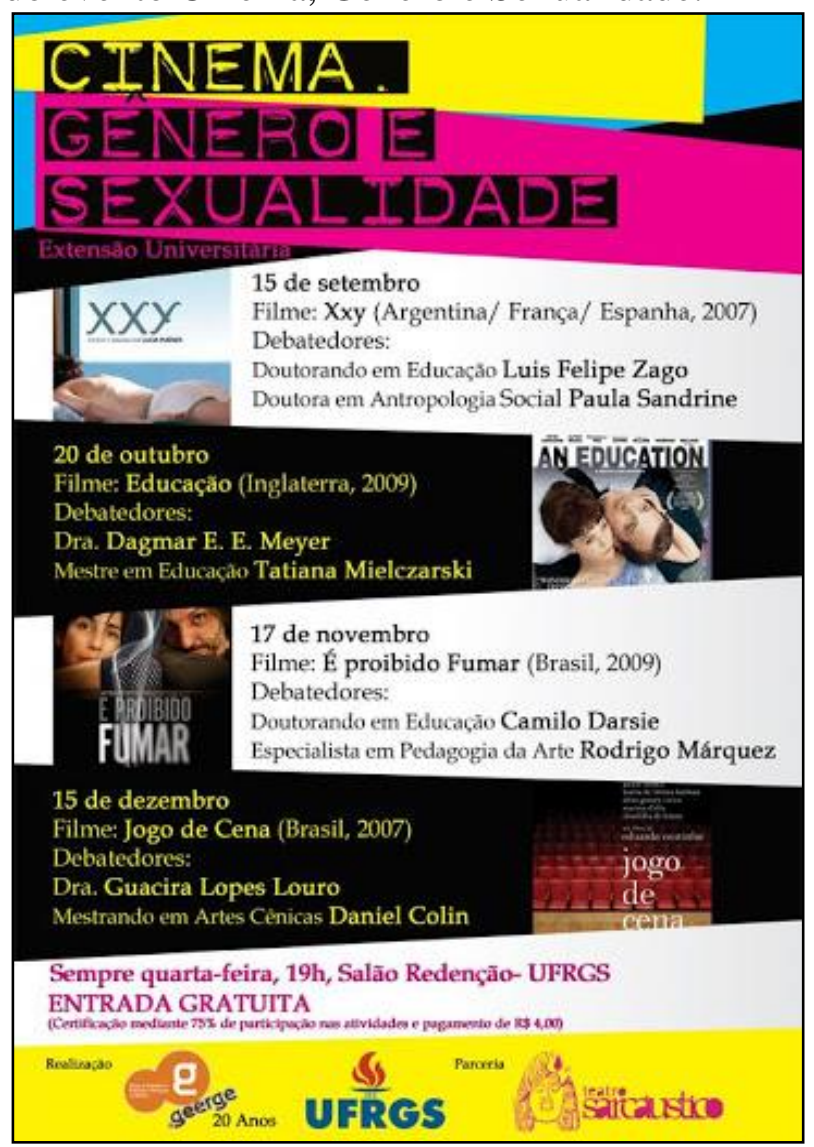

FONTE: Blog do Curso de Especialização (2010). ${ }^{6}$

A referida atividade contou com discentes de outros cursos da instituição, assim como alunos/as de outras IES, dando visibilidade ao grupo de estudos da UFRGS

\footnotetext{
${ }^{6}$ Disponível em: <http://cursoespecializacaogeerge.blogspot.com>. Acesso em: 7 nov. 2018.
} 
e também proporcionando horas complementares a acadêmicos, assim como fomentando pesquisas e divulgando produções da academia e da militância em prol das questões abordadas nos filmes e debatidas posteriormente nas sessões.

\section{TOMADAS METODOLÓGICAS}

Como metodologia para este estudo, buscamos, por meio de uma pesquisa bibliográfica, teorizações sobre a utilização das artes para o debate acerca das questões de gênero e sexualidade, principalmente do cinema operado como artefato e pedagogia cultural. Destacamos as produções de Balestrin (2009; 2014), Brasun e Kiske (2017), Duarte (2009), Ellsworth (2001), Lopes (2006), Louro (2008; 2000), Marcelo e Fischer (2011), Meyer e Soares (2005), Napolitano (2009), Pinto e Pereira (2005), Silva (2001) e Xavier Filha (2014).

\section{PLANOS DE ANALISE E DE DISCUSSÃO EM TELA}

A atividade com filmes que o Ciclo de Cinema do GEERGE propôs em suas cinco edições, entre 2004 e 2009, contribuiu muito para um potente debate acerca das questões de gênero e sexualidade, uma vez que o cinema, assim como a internet e a televisão, por exemplo, interpela os sujeitos de diferentes maneiras e colocam em funcionamento certas estratégias de regulação social (LOURO, 2001).

Devemos pensar no cinema não somente como um espaço, normalmente dentro de um shopping, cujo ingresso não é sempre tão acessível a todas as classes sociais, mas sim como um produtor de cultura, presente também em casas e outros lugares públicos e privados, que revela não apenas realidades nunca antes imaginadas, mas também desejos e necessidades de experiências que tomam como base a nossa vivência para que novas narrativas sejam (re)(des)construídas.

Desta maneira, compreendemos aqui o cinema não como uma arte ou uma cultura criadora de representações de gênero e sexualidade, mas com uma função que critica e/ou reafirma os clichês dessas representações (LOPES, 2006). Assim, o espectador também é convidado a pensar acerca das performances convencionadas no gênero e na sexualidade - assim como outros marcadores presentes nas tramas - tanto de protagonistas quanto de personagens coadjuvantes.

Considera-se neste estudo o filme como um artefato cultural, pois como destaca Silva (2001, p. 140), o referido conceito "transmite uma variedade de formas 
de conhecimento que embora não sejam reconhecidos como tais, são vitais na formação de identidade e subjetividade". Nesse sentido, seria possível entender a produção cinematográfica

Como destaca Louro (2008, p. 94)

$\mathrm{Na}$ contemporaneidade, o cinema, como tantas outras instâncias, pluraliza suas representações sobre a sexualidade e os gêneros. Por toda parte (e também nos filmes) proliferam possibilidades de sujeitos, de práticas, de arranjos e, como seria de se esperar, proliferam questões.

Por meio das narrativas fílmicas podemos (re)conhecer a nós mesmos e aos outros, podemos perceber (re)ações adversas a diferentes situações cotidianas, podemos identificar disposições diversas acerca do que temos como convencionado, assim como podemos apontar e questionar tópicos de nossas vidas nunca antes pensados ou problematizados.

Sendo um artefato cultural com alcance de um público amplo, o filme opera com diferentes "modos de endereçamento" (ELLSWORTH, 2001), interpelando tanto homens quanto mulheres, jovens e idosos, brancos e negros, heterossexuais e homossexuais, e toda uma infinidade de modos de ser e de viver que há na contemporaneidade e dentre os extremos do binarismo.

Esses "modos de endereçamento", na perspectiva do Ciclo de Cinema do GEERGE, era um ponto muito importante na organização do evento, pois precisava abraçar um público que vinha de dentro e de fora da instituição, e que não havia um perfil específico prévio, uma vez que não era necessária uma inscrição para participar das sessões.

Duarte (2002, p. 17) afirma que "ver filmes é uma prática social tão importante, do ponto de vista da formação cultural e educacional das pessoas, quanto à leitura de obras literárias, filosóficas, sociólogas e tantas mais". Poderíamos também pensar e analisar a partir de uma ótica da leitura dos filmes e de todos os elementos que o compõe, levando em conta as intencionalidades da produção por trás do audiovisual.

Nesse sentido, Ellsworth (2011, p. 31) ainda salienta que

Não importa quanto o modo de endereçamento do filme tente construir uma posição fixa e coerente no interior do conhecimento, do gênero, da raça, da sexualidade, a partir da qual o filme "deve" ser lido: os espectadores reais sempre leram os filmes em direção contrária a seus modos de endereçamento, "respondendo" aos filmes a partir de lugares que são diferentes daqueles a partir dos quais o filme fala ao espectador. 
A proposta do Ciclo de Cinema do GEERGE conversa com o que Marcello e Fischer (2011, p. 511) salientam sobre a potência de investigar cinema e educação, uma vez que a imagem dá "a possibilidade de nos oferecer outros modos de pensar - para além da confirmação do que, antes dela, já sabíamos, algo em que já acreditávamos".

Com a exibição de filmes que problematizavam gênero e sexualidade, foi possível oportunizar maneiras diferentes de visualizar as possibilidades de viver essas questões, como essas vivências eram e são construídas ao longo do tempo e de que forma poderíamos enxergá-las no futuro, analisando também o que acontece no presente que impede uma sociedade que não segrega e nem exclui, mas integra e, acima disso, inclui.

Acerca do uso do cinema na Educação, Napolitano (2009) apresenta duas maneiras para essa metodologia. A primeira sugere que o filme represente um texto gerador de debates sobre temáticas que o/a docente previamente selecionou; enquanto a segunda propõe relacionar o filme a um documento e analisá-lo como produção cultural e estética, investigando conceitos, representações sociais e valores.

No Ciclo de Cinema, os/as participantes sabiam que os debates seriam em torno de jeitos de existir com base em gêneros e sexualidades distintas, portanto o olhar sobre o filme já partia dessa perspectiva atenta e sensível. Como atentam Meyer e Soares (2005), sempre partimos de pistas e suspeitas quando investigamos algo que nos provoca, desacomoda, instiga ou nos coloca interrogações.

É interessante pensar como tudo o que está (pro)posto na produção cinematográfica tem a sua finalidade, tem o seu interesse. O convite ao espectador que assiste ao filme envolve inúmeras cenas, diálogos, cenários e detalhes que por vezes passam despercebidos a olhos menos atentos. Uma fala, um trejeito, uma escolha de roupa ou de local, tudo está lá para que o sujeito que assista pense sobre e evolua.

Xavier Filha (2014, p. 12) afirma que

As imagens, em movimento ou não, por já fazerem parte de nossas vidas, nos afetam e também nos educam e são instrumentos de pedagogias culturais. Os filmes são importantes artefatos culturais que estão a nos dizer quem devemos ser, como nos comportar, como ser meninas-mulheres, meninos-homens de determinados jeitos, enfim, instigam-nos a pensar sobre o que somos e o que queremos ser.

Durante muito tempo, como aponta Louro (2001), o cinema hollywoodiano era, fundamentalmente, construído a partir de uma ótica branca, classe média, heterossexual e masculina. $\mathrm{Na}$ contemporaneidade, é possível perceber que tanto a produção 
quanto a atuação em filmes demonstra uma nova perspectiva artística, uma vez que agora são encenadas outras formas de sexualidade que antes eram proibidas para homens e mulheres. "Personagens gays e lésbicas não apenas se tornam 'visíveis' mas algumas vezes são personagens centrais na trama” (LOURO, 2001, pp. 441-442).

Como mencionado anteriormente, entre 2008 e 2011 o GEERGE ofertou duas edições de um curso de especialização com o mesmo nome da linha de pesquisa do PPGEDU, "Educação, Sexualidade e Relações de Gênero", que tinha a carga horária de 375 horas. As aulas da pós-graduação latu senso, coordenada pela professora Rosângela Soares, ocorria nas sextas-feiras à noite e aos sábados pela manhã, com professores da FACED/UFRGS e alguns convidados.

Uma das disciplinas do curso chamava-se "Cinema e Pedagogias da Sexualidade", ministrada pela professora Guacira Lopes Louro. De acordo com ementa disponível no blog do curso ${ }^{7}$

O cinema é compreendido, nesta disciplina, como importante instância pedagógica da contemporaneidade. A partir de teóricas/os dos campos de estudos feministas, gays, lésbicos e queer, pretende-se analisar o cinema como prática social e como texto, discutindo, muito especialmente, representações de gênero e sexualidade, processos de heteronormatividade e homofobia, pornografia e erotismo, censura e transgressão produzidos, veiculados e em ação nos filmes.

Balestrin (2009, p. 176) salienta que "os filmes, enquanto artefatos culturais são produtos da cultura que veiculam determinadas representações e que têm 'efeitos de verdades"”. Assim, a autora destaca que essas produções fazem parte do que têm sido chamados de "pedagogias culturais", pois educam a partir da ótica que o sujeito espectador compreende da narrativa que lhe é apresentada em tela.

Por mais que haja uma pedagogia do cinema, esta atua de diferentes formas sobre aqueles que assistem a um filme. É preciso que se verifiquem as próprias experiências e vivências para conseguir estabelecer (novas) formas de compreender distintas realidades, uma vez que somos capturados por falas e imagens que defendem e disputam um ponto de vista específico e que, intencionalmente, despertam variadas reações.

Como salienta Napolitano (2009, p. 12)

a experiência do cinema pode ser ambígua. Por um lado, é subjetiva, emocional, fantasiosa. Por outro, é objetiva (pois nossos olhos vêem as imagens), racional (pois os filmes, geralmente, contam uma história a ser compreendida pelo espectador) e realista (pois a encenação nos transporta para outras realidades).

\footnotetext{
${ }^{7}$ Disponível em: <http://cursoespecializacaogeerge.blogspot.com>. Acesso em: 25 out. 2018.
} 
Assim, seria interessante pensar no cinema por meio de uma visão de (des)construção daquilo que temos como convencionado, por exemplo, no campo das sexualidades. Balestrin e Soares $(2014$, p. 93) indicam que "o cinema, como uma arte e uma forma específica de linguagem, possui a potência para romper com e ressignificar determinadas construções sociais já existentes”.

Nesse sentido, podemos falar tanto de resistência quanto de subversões de ordens normativas com as quais somos colocados a negociar desde a infância a partir de longas-metragens. Apesar dessa visão desestabilizadora, a pedagogia exercida pelo cinema, conforme nos mostra Louro (2001, p. 443), não extinguiu seu poder de sedução, seu apelo e sua popularidade, pois

Quando se examinam os diferentes processos educacionais que constituíram a sociedade brasileira, parece importante observar criticamente não apenas as vozes do passado, mas quem está, ainda hoje, falando por meio dessa pedagogia cultural e que efeitos ela está potencialmente produzindo.

No Ciclo de Cinema do GEERGE, o cinema assume papel fundamental para a proposição de objeto de análise e estudo a partir de retratos reais ou ficcionais de vivências acerca de gênero e sexualidade. Tendo a sétima arte uma linguagem própria, que atinge de maneira direta e fácil diferentes públicos, a possibilidade de suscitar no espectador reflexões sobre o outro e, acima disso, sobre si mesmo.

Sobre a prática de utilizar a linguagem do cinema como conteúdo, Pinto e Pereira (2005, p. 112) destacam que

precisamos ter em mãos uma teoria estética que nos possibilite realizar análises filmísticas que tematizem o "corpo" e a educação deste. Seja, desmistificando o cinema enquanto produto e constituinte da indústria cultural, seja promovendo o cinema enquanto arte.

O trabalho com o cinema no campo da Educação é um terreno fértil ainda a ser explorado, pois por vezes as imagens em movimento não recebem a devida atenção e se perdem nas abordagens superficiais que são realizadas.

Braun e Keske (2017, pp. 234-235) destacam que o cinema tem possibilitado a prática de diversas funções em seus espectadores, como a educação, o entretenimento e a informação. "Porém, muitas vezes, preocupa-se mais com o entretenimento das massas, do que pela catarse que poderia provocar e, consequentemente, com os resultados que viriam a se concretizar na prática social”.

Concebido de uma maneira geral muito mais pela sua ótica do entretenimento do que pela da educação e da informação, o cinema, por vezes, é subestimado 
como sendo uma arte pura e somente para lazer, um programa de final de semana. Porém, o conteúdo de um filme indica uma oportunidade de aprendizado e crescimento, principalmente de debate sobre modos de ser e viver.

Em um estudo sobre os filmes "Má Educação" (Espanha, 2004) e "Tudo Sobre Minha Mãe” (Espanha, 1999) de Pedro Almodóvar, Braun e Keske (2017, p. 251) apontam que há uma forma de fazer cinema muito além do entretenimento

\begin{abstract}
ao apresentar e retratar fatos concretos de nossas sociedades, o fazer de maneira a apresentar tais fatos e personagens como perfeitamente inseridos em nosso cotidiano, nos leva a pensar em desconsiderar o tratamento de exclusão a que são sistematicamente submetidos, somente por se apresentarem de outra maneira que não a socialmente admitida.
\end{abstract}

Portanto, seja considerando arte, artefato, produção cultural ou pedagogia, o cinema tratado no Ciclo de Cinema do GEERGE abraçou todas essas possibilidades de interpretação e ainda foi além, propôs uma inovação a partir de atividade dirigida a um público diverso permeado de conhecimentos advindos da academia e da militância, da experiência dos/as organizadores/as e dos/as debatedores/as.

\title{
PRODUÇÕES SOBRE CINEMA, EDUCAÇÃO, GÊNERO E SEXUALIDADE
}

No âmbito da linha de pesquisa Educação, Sexualidade e Relações de Gênero, três teses já foram produzidas abordando o cinema relacionado com os campos de estudos sobre gênero e sexualidade: uma analisando os filmes infantis e a produção performativa da heterossexualidade (SABAT, 2003); outra sobre a constituição de uma suposta identidade da 'mulher brasileira' (BALESTRIN, 2012); e uma última que investigava os corpos femininos nas telas do cinema (FRIEDERICHS, 2015).

Assim, é possível perceber as inúmeras possibilidades que a produção fílmica oferece às pesquisas acadêmicas na produção de conhecimento, em especial na Educação e para o debate acerca das questões de gênero e sexualidade; da mesma maneira que a literatura também oportuniza esse trabalho.

Destacamos, aqui, duas dissertações e uma tese - produzidas por alunas da linha de pesquisa - que operam com a literatura nesse sentido: uma que objetivava compreender quais os significados de gênero que crianças de 4 a 6 anos atribuíram a histórias infantis não-sexistas (ARGÜELLO, 2005); outra que problematizava as diferentes representações, advindas de materiais da Literatura Infanto-juvenil, e como essas operam discursivamente 
na constituição das identidades masculinas e paternas (SEFTON, 2006); e uma terceira que investigava como são representadas as relações amorosas românticas presentes em textos de literatura infantil contemporâneos (PIRES, 2009).

Quase uma década depois da última edição do Ciclo de Cinema do GEERGE, em 2017 a professora Guacira Lopes Louro lançou o livro "Flor de Açafrão: takes, cuts, close-ups", pela Editora Autêntica. Na obra, a professora aborda o cinema e a literatura - por meio de narrativas nacionais e internacionais, antigas e modernas - como fonte para tecer considerações sobre como as questões de gênero e sexualidade eram e são representadas nessas artes, mas sem deixar de operar com teorizações desses campos.

No mesmo ano, a professora Jane Felipe também publicou alguns contos de sua autoria na coletânea "Escândalos Reinventados", organizada por Pedro Gonzaga e lançada pela Editora Class. Em seus escritos no livro, a professora aborda, por meio da literatura, algumas questões com as quais tem trabalhado no meio acadêmico; por exemplo, no texto "Abrem-se as cortinas: primeiro ato", fala sobre casamento, maternidade e pedofilia; em "Conto do Vigário", ela aborda novamente a pedofilia; no texto "La corna victoriosa", podemos ler sobre casamento.

Já em 2018, o professor Fernando Seffner, juntamente com dois de seus bolsistas, os também professores João Paulo Buchholz e Otavio Klein Travi, lançaram no YouTube o canal Território Escolar, que, de acordo com descrição oficial na rede social de vídeos, é "um espaço onde se discutem questões envolvendo escola, políticas públicas de educação, cultura escolar, formação docente, culturas juvenis, o ensinar e o aprender, sob perspectiva pedagógica e política". ${ }^{8}$

Assim, podemos perceber como as artes, seja o cinema ou a literatura, têm desempenhado um papel fundamental para as problematizações de gênero e sexualidade. Da mesma forma que a academia e o ativismo se relacionam, a academia e a literatura também possuem um laço que, juntas, oportunizam e potencializam os debates e as (des)construções de conhecimentos acerca dessas temáticas.

\section{ANTES DE SUBIR OS CRÉDITOS}

A realização do Ciclo de Cinema do GEERGE, entre os anos de 2004 e 2009, propiciou debates acerca das questões de gênero e sexualidade de dentro para fora

\footnotetext{
${ }^{8}$ Disponível em: <http://www.youtube.com/channel/UCV-JxhGvkG0u3N2_8VluDzw〉. Acesso em 28 out. 2018.
} 
da academia, oportunizando o acesso aos estudos do grupo e da linha de pesquisa à comunidade em geral, compartilhando culturas, leituras e teorizações atuais e relevantes para o cenário brasileiro.

O evento, em geral, possibilitou também ao público presente nas exibições e nos debates entender algumas sutilezas das quais o cinema retrata tão bem, pois como a discussão era em torno das temáticas gênero e sexualidade, era possível compreender como essas questões eram representadas por meio de diversas culturas e variados tempos, perpassando interesses e valores.

Com base nesse estudo, podemos afirmar que o Ciclo de Cinema do GEERGE foi um evento que proporcionou não somente sessões de filmes e debates sobre gênero e sexualidade, mas também a (des)construção de conhecimentos, experiências e pensamentos acerca dessas questões para um público bastante diverso que, a partir das vivências na Sala Redenção da UFRGS, pode estar em contato - e imaginamos que alguns pela primeira vez - com temáticas tão importantes e presentes em nosso cotidiano, seja nas relações de poder ou no contato com a diversidade, por meio de pesquisadores/as e professores/as que se dedicam a esses estudos.

Por fim, acreditamos que a proposta do Ciclo de Cinema do GEERGE foi operar com a arte cinematográfica como proposição de novos e outros olhares a uma pedagogia que borre e escape de uma (re)produção de estereótipos excludentes na sociedade com base em gênero e sexualidade. Assim, indagamos: que outros olhares e outras vivências poderiam ser pensadas a partir do cinema?

\section{REFERÊNCIAS}

ARGÜELLO, Zandra Elisa Argüello. Dialogando com crianças sobre gênero através da literatura infantil. 2005. 193 f. Dissertação (Mestrado em Educação) Universidade Federal do Rio Grande do Sul: Porto Alegre, 2005.

BALESTRIN, Patrícia Abel. Gênero e sexualidade no cinema: questões para a educação. In: XAVIER FILHA, Constantina (org.). Educação para sexualidade, para a equidade de gênero e para a diversidade sexual. Campo Grande: UFMS, 2009. p. 175-192.

BALESTRIN, Patrícia Abel. O corpo rifado. 2012. 177 f. Tese (Doutorado em Educação) - Universidade Federal do Rio Grande do Sul: Porto Alegre, 2012.

BALESTRIN, Patrícia Abel; SOARES, Rosângela. "Etnografia de tela": uma proposta metodológica. In: MEYER, Dagmar Estermann; PARAÍSO, Marlucy Alves (orgs.). Metodologias de pesquisas pós-críticas em educação. 2. ed. Belo Horizonte: Mazza Edições, 2014. p. 89-111. 
BRAUN, Eduarda Djovana; KESKE, Henrique Alexander. O cinema de Pedro Almodóvar e a representatividade de gênero e sexualidade através dos filmes Má Educação (2004) e Tudo Sobre Minha Mãe (1999). In: RUBLESCKI, Anelise; KESKE, Henrique Alexander (orgs.). Trilhas e caminhos da comunicação: comunicação em debate. Novo Hamburgo: Feevale, 2017. p. 231-252.

DUARTE, Rosália. Cinema \& educação. Belo Horizonte: Autêntica, 2002.

ELLSWORTH, Elizabeth. Modos de endereçamento: uma coisa de cinema; uma coisa de educação também. In: SILVA, Tomaz Tadeu da (org). Nunca fomos humanos: nos rastros do sujeito. Belo Horizonte: Autêntica, 2001. p. 8-76.

FELIPE, Jane. O GEERGE. In: RIBEIRO, Paula Regina Costa ... [et al] (Org.). Corpo, gênero e sexualidade: discutindo práticas educativas. Rio Grande: FURG, 2007. p. 123-125

FRIEDERICHS, Marta Cristina. Quanto mais quente melhor: corpos femininos nas telas do cinema. 2015. 207 f. Tese (Doutorado em Educação) - Universidade Federal do Rio Grande do Sul: Porto Alegre, 2015.

GONZAGA, Pedro (org.). Escândalos reinventados. Porto Alegre: Class, 2017.

LOPES, Denílson. Cinema e gênero. In: MASCARELLO, Fernando (org.). História do Cinema mundial. Campinas: Papirus, 2006. p. 379-394.

LOURO, Guacira Lopes. Cinema e Sexualidade. Educação \& Realidade. Porto Alegre, v. 33, n. 1, p. 81-98. jan/jun 2008.

LOURO, Guacira Lopes. Flor de açafrão: takes, cuts e close-ups. Belo Horizonte: Autêntica, 2017.

LOURO, Guacira Lopes. O cinema como pedagogia. In: LOPES, Eliane Marta Teixeira; FARIA FILHO, Luciano Mendes; VEIGA, Cynthia Greive (orgs.). 500 anos de educação no Brasil. 2. ed. Belo Horizonte: Autêntica, 2000. (Coleção Historial, 6) p. 423-446.

MARCELLO, Fabiana de Amorim; FISCHER, Rosa Maria Bueno. Tópicos para Pensar a Pesquisa em Cinema e Educação. Educação \& Realidade, Porto Alegre, v. 36, n. 2, p. 505-519, maio/ago. 2011.

MEYER, Dagmar E. Estermann; SOARES, Rosângela de Fátima. Modos de ver e se movimentar pelos caminhos da pesquisa pós-estruturalista em educação: o que podemos aprender com e a partir de um filme. In: COSTA, Marisa Vorraber; BUJES, Maria Isabel Edelweiss (orgs.). Caminhos investigativos III: riscos e possibilidades de pesquisar nas fronteiras. Rio de Janeiro: DP\&A, 2005. p. 23-44.

NAPOLITANO, Marcos. Cinema: experiência cultural e escolar. In: TOZZI, Devanil (org.). Caderno de Cinema do Professor: dois. São Paulo: FDE, 2009. p. 20-31.

PINTO, Fábio Machado; PEREIRA, Lana Gomes. A experiência de ver filmes na formação inicial de professores de educação Física. Pensar a prática. v. 8. n. 1. jan./jun. 2005. p. 101-116.

PIRES, Suyan Maria Ferreira. "Histórias de amor para sempre, histórias de amor para nunca mais...": o amor romântico na literatura infantil. 2009. 191 f. Tese (Doutorado em Educação) - Universidade Federal do Rio Grande do Sul: Porto Alegre, 2009.

SABAT, Ruth Francini Ramos. Filmes infantis e a produção performativa da heterossexualidade. 2003. 185 f. Tese (Doutorado em Educação) - Universidade Federal do Rio Grande do Sul: Porto Alegre, 2003. 
SEFTON, Ana Paula. "Pai não é de uso diário"(?): paternidades na literatura infantojuvenil. 2006. 146 f. Dissertação (Mestrado em Educação) - Universidade Federal do Rio Grande do Sul: Porto Alegre, 2006.

SILVA, Tomaz Tadeu da. Documentos de identidade: uma introdução às teorias currículo. Belo Horizonte: Autêntica, 2001.

XAVIER FILHA, Constantina. Luz, Câmera, ação... Problematizando Sexualidades, Gênero e Infâncias no Cinema: Desejo de "Desver" o Mundo. In: XAVIER FILHA, Constantina. Sexualidade, gênero e infâncias no cinema (org.). Campo Grande: UFMS, 2014. p. 9-14. 